\title{
A Novel Fading Memory Recursive Least Square Method (FMLS) for Accurate State of Charge Estimation of Lithium- ion Batteries Combined with Improved Second Order PNGV M odeling
}

\author{
Donglei Liu, Yongcun Fan ${ }^{*}$, Shunli Wang ${ }^{*}$, Lili Xia, Jingsong Qiu, Etse Dablu Bobobee \\ School of Information Engineering, Southwest University of Science and Technology, Mianyang \\ 621010, China \\ *E-mail:111064@qq.com, 497420789@qq.com.
}

Received: 27 May 2021 / Accepted: 9 July 2021 / Published: 10 August 2021

\begin{abstract}
As the main energy storage element and power source of electric vehicles, the accurate estimation of the state of charge (SOC) of lithium-ion batteries is very important for the battery management system of electric vehicles, as well as for the driving range and safety. To accurately describe the characteristics of the lithium-ion battery, an improved PNGV model was formed by connecting an RC circuit based on the traditional PNGV lithium battery equivalent model. Considering the aging characteristics of lithium batteries in use, the recursive least square method (FMRLS) with fading memory was adopted to identify parameters to meet the requirements of estimation accuracy, and the Extended Kalman Filter (EKF) algorithm was used to estimate SOC. The accuracy of MAE, MAPE and RMSE was improved by $9.21 \%$, $4.85 \%$ and $9.38 \%$ respectively under DST condition. The improvement was $34.35 \%, 36.59 \%$ and $31.97 \%$, respectively, Under BBDST condition.
\end{abstract}

Keywords: lithium-ion batteries; state of charge estimation; electrical equivalent circuit model; FMRLS; Extended Kalman filter

\section{FULL TEXT}

(C) 2021 The Authors. Published by ESG (www.electrochemsci.org). This article is an open access article distributed under the terms and conditions of the Creative Commons Attribution license (http://creativecommons.org/licenses/by/4.0/). 